\title{
D-Tryptophan enhances the reproductive organ-specific expression of the amino acid transporter homolog Dr-SLC38A9 involved in the sexual induction of planarian Dugesia ryukyuensis
}

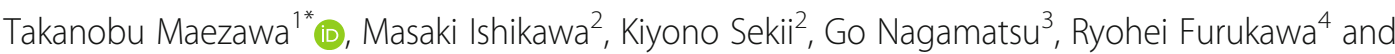 \\ Kazuya Kobayashi ${ }^{*}$
}

\begin{abstract}
Background: Many animals switch between asexual and sexual reproduction in nature. We previously established a system for the sexual induction of planarian Dugesia ryukyuensis by feeding asexual planarians with minced sexual planarians. We identified DL-tryptophan (Trp) as one of the sex-inducing substances. DL-Trp can induce ovarian development, the first and essential step of sexual induction. D-Trp must act as a principal bioactive compound in terms of ovarian development, because the ovary-inducing activity of D-Trp was 500 times more potent than that of L-Trp. However, how Trp controls sexual induction is still unknown.

Results: In this study, qRT-PCR analyses suggested that the putative amino acid transporter gene Dr-SLC38A9 is highly expressed in sexual worms, especially in the yolk glands. In situ hybridization analyses showed that Dr-SLC38A9 is expressed in the ovarian primordia of asexual worms and in the mature ovaries, testes, and yolk glands of sexual worms. In addition, Dr-SLC38A9 RNA interference during sexual induction resulted in the suppression of the development of reproductive organs. These results suggest that Dr-SLC38A9 is involved in the development of these organs. Moreover, we demonstrated that the reproductive organ-specific expression of Dr-SLC38A9 is enhanced by the addition of D-Trp.

Conclusion: We propose that D-Trp activates the expression of Dr-SLC38A9 to promote sexual induction in the planarian D. nyukyuensis.
\end{abstract}

Keywords: Planarian, Sexual induction, Germ cell, Amino acid transporter, Tryptophan

\footnotetext{
* Correspondence: maezawa@tsuyama-ct.ac.jp; kobkyram@hirosaki-u.ac.jp

${ }^{1}$ Advanced Science Course, Department of Integrated Science and

Technology, National Institute of Technology, Tsuyama College, 624-1 Numa,

Tsuyama, Okayama 708-8509, Japan

${ }^{2}$ Faculty of Agriculture and Life Science, Hirosaki University, 3 Bunkyo-cho,

Hirosaki, Aomori 036-8561, Japan

Full list of author information is available at the end of the article
}

C The Author(s). 2021 Open Access This article is licensed under a Creative Commons Attribution 4.0 International License, which permits use, sharing, adaptation, distribution and reproduction in any medium or format, as long as you give appropriate credit to the original author(s) and the source, provide a link to the Creative Commons licence, and indicate if changes were made. The images or other third party material in this article are included in the article's Creative Commons licence, unless indicated otherwise in a credit line to the material. If material is not included in the article's Creative Commons licence and your intended use is not permitted by statutory regulation or exceeds the permitted use, you will need to obtain permission directly from the copyright holder. To view a copy of this licence, visit http://creativecommons.org/licenses/by/4.0/. The Creative Commons Public Domain Dedication waiver (http://creativecommons.org/publicdomain/zero/1.0/) applies to the data made available in this article, unless otherwise stated in a credit line to the data. 


\section{Background}

Many animals switch between asexual and sexual reproduction, depending on environmental conditions and/or the phase of their life cycle [1-4]. The switching of reproductive modes might be a way to take advantage of both forms of reproduction. However, the underlying mechanisms are poorly understood [1].

Certain freshwater planarians reproduce both asexually and sexually. Asexual planarians reproduce by dividing their body into two parts: each part regenerates the lost half. This regenerative ability is afforded by pluripotent stem cells known as neoblasts $[5,6]$. Sexual planarians possess hermaphroditic reproductive organs and copulate with other sexual planarians. Reproductive organs are differentiated from neoblasts postembryonically, in the juvenile stage [7]. Some asexual planarians may develop hermaphroditic reproductive organs from neoblasts in the adult stage and undergo sexual reproduction, depending on environmental conditions [8-13]. Reproductive mode switching rarely occurs under controlled laboratory conditions. Therefore, methods to induce sexual development in asexual worms have contributed to our understanding of reproductive switching [14-17]. We previously established a biological assay system to sexually switch an asexual clonal population of Dugesia ryukyuensis (OH strain) by feeding with the minced bodies of sexually mature worms of the species Bdellocephala brunnea [1]. The occurrence of the switch indicates that sexually mature worms contain one or more chemicals that stimulate sexual induction in $\mathrm{OH}$ worms, and we defined these chemical(s) to be sex-inducing substance(s). During sexual induction, within approximately 1 month, asexual worms develop a pair of ovaries, yolk glands, testes, copulatory apparatus, and a genital pore, in that order (Fig. S1) [18, 19]. This sex-induction process is divided into five stages (Fig. S1) [18, 19]. Sexually mature worms successfully copulate with each other and eventually lay cocoons (ectolecithal eggs) containing several fertilized eggs and numerous yolk gland cells. Yolk gland cells are produced in the yolk gland, which is a reproductive organ unique to planarians [20, 21].

In a previous study, we found that the feeding of fresh cocoons containing numerous yolk gland cells to asexual worms caused their full sexual induction [22]. This result suggests that yolk gland cells might contain sexinducing substance(s) that trigger full sexual induction. We carried out bioassay-guided fractionation to identify the sex-inducing substance(s) contained in B. brunnea and identified tryptophan (Trp) as a sex-inducing substance based on electrospray ionization-mass spectrometry (ESI-MS) and nuclear magnetic resonance (NMR) analyses [23]. Furthermore, we found that B. brunnea contained $0.5 \% \mathrm{D}-\operatorname{Trp}$ relative to $\mathrm{L}-\operatorname{Trp}(\mathrm{w} / \mathrm{w})$ by reversephase high-performance liquid chromatography (HPLC).
Through feeding DL-Trp, asexual worms were induced to stage 1-2 worms presenting immature ovaries, which suggests that DL-Trp is involved in ovarian development, the first step of sexual induction. Interestingly, D-Trp must act as a principal bioactive compound in terms of ovarian development, because the ovary-inducing activity of D-Trp was 500 times more potent than that of LTrp. However, how Trp controls sexual induction is still unknown. We found that Trp is enriched in the yolk glands of stage 5 (sexual) worms of D. ryukyuensis [23]. Trp is an essential amino acid and cannot be produced in animal bodies. Considering the enrichment of Trp in yolk glands and the ovary-inducing activity of Trp, we hypothesized that ovaries and yolk glands express a specific amino acid transporter. Therefore, in the present study, we isolated a candidate amino acid transporter gene and analyzed its expression and function during sexual induction.

\section{Methods \\ Animals}

An exclusively asexual strain of the planarian $D$. ryukyuensis (OH strain) [24, 25] was established by Dr. S. Ishida at Hirosaki University (Hirosaki, Japan). The $\mathrm{OH}$ strain was cultured at $20^{\circ} \mathrm{C}$ in dechlorinated tap water. Asexual worms were fed chicken liver once per week. Sexual D. ryukyuensis worms were induced from asexual worms by feeding them minced B. brunnea worms [26]. In the sexual induction assay, five individuals of approximately $5 \mathrm{~mm}$ in body length were placed in a $90 \mathrm{~mm}$ plastic dish and fed daily with $10 \mathrm{mg}$ (wet weight) of minced B. brunnea worms for a month [1].

\section{Cloning of $D$. ryukyuensis SLC38A9 CDNA}

Total RNA was extracted from sexual D. ryukyuensis worms using the Sepasol RNA I Super Extraction Kit (Nacalai Tesque, Kyoto, Japan). First-strand cDNA was prepared from total RNA using random primers and reverse transcriptase (Toyobo, Osaka, Japan). The cDNA of D. ryukyuensis SLC38A9 (Dr-SLC38A9) was amplified by PCR using first-strand CDNA as a template and the primers 5' - CCGGAACGCAGAGTAGTTTC - 3' (forward) and 5' - GCCGAGAGCATTAAATTTGG - 3' (reverse). This primer set was designed based on the sequence of TR38642|c0_g1_i2 from RNA-seq of $D$. ryukyuensis [27]. The PCR protocol was as follows: $94{ }^{\circ} \mathrm{C}$ for $2 \mathrm{~min}$, followed by 30 cycles of $94^{\circ} \mathrm{C}$ for $30 \mathrm{~s}, 55^{\circ} \mathrm{C}$ for $30 \mathrm{~s}$, and $68^{\circ} \mathrm{C}$ for $1 \mathrm{~min}$. Full-length sequences of the genes were obtained using $3^{\prime}$ and $5^{\prime}$ - rapid amplification of cDNA ends (RACE) using the SMART ${ }^{\mathrm{TM}}$ RACE cDNA Amplification kit (Clontech, Mountain View, CA, USA) and the following primer set: Dr-SLC38A9 5RACE, GTTCGACCGGGCTCCAGAGGTAAAT; and Dr-SLC38A9_3RACE, 5'-TGATCACTTTGCCCGCAT 
TGGTG-3'. The nucleotide sequence of $D r-S L C 38 A 9$ reported in this paper has been deposited in the DDBJ nucleotide sequence database (accession number LC225747; https://www.ddbj.nig.ac.jp/index-e.html). Homology searches for Dr-SLC38A9 were performed using the NCBI BLASTp program (https://blast.ncbi.nlm.nih.gov/ Blast.cgi). We obtained sequences of SLC38A9 homologs in humans, mice, and zebrafish and of SLC38 family members in the planarian Schmidtea mediterranea from the NCBI database (https://www.ncbi.nlm.nih.gov). Phylogenetic trees of human and planarian S. mediterranea SLC38 proteins [28] and Dr-SLC38A9 of planarian D. ryukyuensis were constructed using the neighbor-joining method [29] in ClustalW (https://www.genome.jp/tools-bin/clustalw). Protein sequences were aligned using ClustalW.

\section{Quantitative reverse-transcription PCR}

Quantitative reverse-transcription PCR (qRT-PCR) was performed using the 7300 Real-Time PCR System (Applied Biosystems, Foster City, CA, USA). Each reaction mixture $(25 \mu \mathrm{L})$ contained $12.5 \mu \mathrm{L}$ of Power SYBR Green PCR Master mix (Applied Biosystems), $0.4 \mu \mathrm{M}$ genespecific primers, and $0.5 \mu \mathrm{L}$ of cDNA template. Planarian cDNA was prepared as described above. The PCR protocol was as follows: $50^{\circ} \mathrm{C}$ for 2 and $95^{\circ} \mathrm{C}$ for 10 , followed by 40 cycles of $95^{\circ} \mathrm{C}$ for $15 \mathrm{~s}$ and $60^{\circ} \mathrm{C}$ for $1 \mathrm{~min}$. Measurements were normalized to the expression levels of glyceraldehyde 3-phosphate dehydrogenase homolog $(G A P D H)$ [30] or elongation factor 1 alpha homolog (Dr-ef1a) [31]. The primers used in the current study are shown in Supplementary Table S1. The raw qRT-PCR analysis data are shown in Supplementary Data Sheet S1.

\section{Statistical analysis}

The between-sample differences in obtained threshold cycle (Ct) values were calculated using the $\Delta \Delta \mathrm{Ct}$ method. Briefly, $\Delta \mathrm{Ct}$ [where $\Delta \mathrm{Ct}=\mathrm{Ct}$ (target gene) $-\mathrm{Ct}$ (internal control)] was calculated for each sample, and then $\Delta \Delta \mathrm{Ct}$ [where $\Delta \Delta \mathrm{Ct}=\Delta \mathrm{Ct}$ (sample) - the average of $\Delta \mathrm{Ct}$ (calibrator)] was calculated. Calibrators were asexual worms (Fig. 1), EGFP knockdown worms (Fig. 4) and liver-fed worms (Fig. 5). Statistical tests were performed on the $\Delta \Delta \mathrm{Ct}$ values. Relative expression was calculated as $2^{-\Delta \Delta \mathrm{Ct}}$. Statistical tests were performed using $\mathrm{R}$ v3.2.2 [32]. The Shapiro-Wilk test was used to validate the normal distributions of the obtained data, and the F-test or Bartlett's test was used to validate the equality of variances. Student's t-test was used to compare gene expression levels between two groups. In some cases, Welch's t-test was used because of unequal variances between the samples. To compare gene expression levels between three groups, one-way ANOVA with post hoc comparison using Tukey's honestly significant difference (HSD) test was conducted.

\section{In situ hybridization and histological analysis}

In situ hybridization of whole-mount worms and sections was performed according to our previously published methods [30, 33]. Sagittal 4- $\mu$ m thick sections were used for in situ hybridization and for hematoxylin and eosin (HE) staining. For in situ hybridization, digoxigenin (DIG)-labeled antisense RNA probes were synthesized using the MEGAscript Kit (Ambion, Austin, TX, USA) from a 695-bp fragment of the open reading frame (ORF, 329-1023) of Dr-SLC38A9. A probe for Dr-nanos was synthesized as previously described [34]. Both probes were hydrolyzed with an equal amount of carbonated buffer $\left(80 \mathrm{mM} \mathrm{NaHCO} 3,120 \mathrm{mM} \mathrm{Na}_{2} \mathrm{CO}_{3}, 10\right.$ $\mathrm{mM}$ DTT) at $60^{\circ} \mathrm{C}$ for $60 \mathrm{~min}$, neutralized and ethanol precipitated. DIG was detected using an alkaline phosphatase (AP)-conjugated anti-DIG antibody (Roche, Mannheim, Germany) and stained blue with NBT/BCIP solution $[17 \mu \mathrm{g} / \mathrm{mL}$ nitro-blue tetrazolium chloride (NBT) and $8.8 \mu \mathrm{g} / \mathrm{mL} 5$-bromo-4-chloro-3-indolyl phosphate, toluidine-salt (BCIP)]. The slides were dipped in
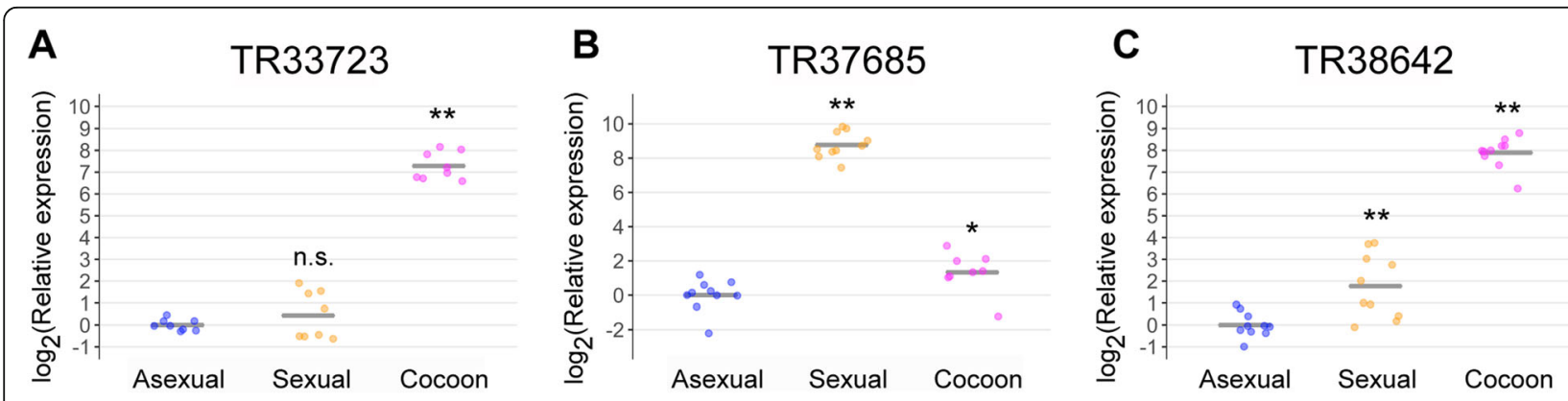

Fig. 1 Comparison of TR33723, TR37685, and TR38642 mRNA levels in asexual worms, sexual worms, and cocoons. qRT-PCR data are shown relative to the expression level (normalized to the Dr-ef1a mRNA level) in the asexual worm; $\log _{2}$ (relative expression) on the vertical axis indicates $-\triangle \Delta C$ t. Each circle indicates an individual asexual worm, sexual worm, or cocoon sample. The bars in the plots indicate the average $-\Delta \Delta \mathrm{Ct}$ values. Asterisks indicate significant differences compared with asexual worms (Tukey's HSD test: ${ }^{* *} P<0.01 ;{ }^{* * *} P<0.001$ ) 
$1 \mu \mathrm{g} / \mathrm{mL}$ Hoechst No. 33342 (Sigma, St. Louis, MO, USA) to counterstain the nuclei.

\section{RNA interference analysis}

Double-stranded RNA (dsRNA) was synthesized in vitro using the MEGAscript High Yield Transcription kit. The Dr-SLC38A9 dsRNAs were a 529-bp fragment (399-927) and 521-bp fragment (1053-1573) of the ORF. The enhanced green fluorescent protein (EGFP) dsRNA was the full-length ORF $(720 \mathrm{bp})$. These dsRNAs were purified using phenol/chloroform and then annealed. To prepare the test foods used for the knockdown experiments under sex-inducing conditions, dsRNAs were added to minced $B$. brunnea and stored at $-80{ }^{\circ} \mathrm{C}$ until use. The worms were fed twice at 2-day intervals with chicken liver supplemented with $200 \mathrm{ng}$ of EGFP or Dr-SLC38A9 dsRNA. On 1 day after the second feeding, the posterior and anterior regions of the worms were amputated, and the trunk fragments were incubated without food for 7 days. The partially regenerated worms were then fed chicken liver supplemented with $200 \mathrm{ng}$ of EGFP or $\mathrm{Dr}$ SLC38A9 dsRNA twice at 2-day intervals to allow the worms to fully regenerate. The resultant asexual worms were then fed minced B. brunnea supplemented with $200 \mathrm{ng}$ of the dsRNAs of the indicated genes daily for 6 weeks.

\section{Preparation of test foods containing sex-inducing substances for the induction of Dr-SLC38A9 expression} The M0 + M10 fraction, which has sex-inducing activity, was prepared from extracts of $B$. brunnea worms $(1 \mathrm{~g}$ wet weight) as previously described [19]. We homogenized B. brunnea worms in phosphate-buffered saline (PBS) and obtained a cytosolic fraction after ultracentrifugation. The cytosolic fraction was desalted and eluted stepwise by changing the methanol concentration of the eluent $(0,10$, and $100 \%(\mathrm{v} / \mathrm{v}))$ on a commercial octadecylsilane (ODS) column, Sep-Pak ${ }^{\bullet}$ Light $\mathrm{tC}_{18}$ Cartridge (Waters, Milford, MA). Strong sex-inducing activity was recovered in the fractions eluted with water and $10 \%$ methanol (M0 fraction and M10 fraction) [19]. The $\mathrm{M} 0+\mathrm{M} 10$ fraction was dried, mixed with $100 \mu \mathrm{L}$ of chicken liver homogenate, and freeze-dried. The food was divided into three portions and used for the experiments. Fifteen sexual worms were fed a portion of food daily over 3 days. After 3 days of treatment, sexual worms were subjected to whole-mount in situ hybridization or qRT-PCR. The L-Trp and D-Trp contents in the $\mathrm{M} 0+\mathrm{M} 10$ fraction from B. brunnea (4 g wet weight) were estimated to be approximately $2 \mathrm{mg}$ and $10 \mu \mathrm{g}$, respectively [23]. Therefore, in this experiment, commercial L-Trp $(500 \mu g$; Nacalai Tesque, Kyoto, Japan) and/or D-Trp (2.5 $\mu \mathrm{g}$; Nacalai Tesque, Kyoto, Japan) were mixed with a $100-\mu \mathrm{L}$ aliquot of chicken liver homogenate, and the respective mixtures were freezedried. The food was divided into three portions and used for the experiments. Fifteen sexual worms were fed together with a daily portion of food for over 3 days. After 3 days of treatment, sexual worms were examined by qRT-PCR.

\section{Results}

Isolation of the putative amino acid transporter gene DrSLC38A9 in D. ryukyuensis

We searched for amino acid transporter genes enriched in sexual planarians using the RNA-seq data of $D$. ryukyuensis [27]. We focused on the DEG (differentially expressed gene) data between asexual and sexual planarians and identified three annotated amino acid transporter genes (TR33723|c0_g1_i1, vesicular inhibitory amino acid transporter; TR37685|c0_g2_i3, excitatory amino acid transporter 2; and TR38642|c0_g1_i2, sodium-coupled neutral amino acid transporter 9 isoform $\times 1$ ). Next, we carried out q-PCR analysis using primers specific to these genes on cDNAs derived from asexual worms, sexual worms, and cocoons (Fig. 1a, b, c). One-way between-subjects ANOVA was conducted to compare the effect of sexual condition on TR33723|c0_g1_i1, TR37685|c0_g2_i3, and TR38642|c0_ g1_i2 gene expression. There was a significant effect of sexual condition on gene expression with $P<0.001$ for the three conditions, with $[\mathrm{F}(2,21)=243.9, P=2.92 \mathrm{e}$ 15], $[\mathrm{F}(2,25)=236.6, P<2 \mathrm{e}-15]$, and $[\mathrm{F}(2,27)=173.3$, $P=3.96 \mathrm{e}-16]$, respectively. Next, to compare the gene expression levels among the three groups, Tukey's honestly significant difference (HSD) test was used. The expression levels in cocoons indicates those in yolk glands because cocoons are mostly filled with yolk gland cells. Considering that tryptophan is enriched in yolk glands [23], we searched for genes that were more highly expressed in cocoons than in asexual and sexual worms, such as Dryg, which is a yolk gland marker gene (Fig. 3S of [35]). Although the relative expression level of TR37685|c0_g2_i3 was significantly higher in both sexual worms (437-fold) and cocoons (2.51-fold) than in asexual worms (Fig. 1b), this expression pattern was not identical to that of Dryg. Thus, TR37685|c0_g2_i3 seems to be expressed in sexual organs other than the yolk glands. The expression of this gene in the cocoons could be attributed to the presence of fertilized eggs. In contrast, as the expression patterns of TR33723|c0_g1_i1 and TR38642|c0_g1_i2 are very similar to that of Dryg, it is expected that these genes will be expressed in yolk glands. Additionally, we sought target genes that are expressed in at least ovaries and yolk glands. The relative expression level of TR33723|c0_g1_i1 in cocoons (156fold) was significantly higher than that in asexual worms. However, the expression in sexual worms was not 
significantly different from that of asexual worms (1.36fold) (Fig. 1a). The relative expression level of TR38642|cO g1_i2 was significantly higher in both sexual worms (3.41fold) and cocoons (238-fold) than in asexual worms (Fig. 1c). Given the potentially higher expression of this gene in yolk glands and ovary-expressed genes, in this study, we decided to focus on TR38642|c0_g1_i2. To confirm the sequence of TR38642|c0_g1_i2, we cloned full-length cDNA from TR38642|c0_g1_i2 mRNA using reverse transcription PCR (RT-PCR) and RACE analyses. The cloned cDNA contains an open reading frame encoding a 585 amino acid (aa) polypeptide that has high homology with human SLC38A9 (73\% identity) [36, 37] (Fig. S2). Therefore, we named this gene Dugesia ryukyuensis SLC38A9 (Dr-SLC38A9). We found that the deduced amino acid sequence of the cloned cDNA has a longer N-terminal region than that of TR38642|c0_g1_i2 from RNA-seq data. Fig. S2 shows the cloned nucleotide sequence and the deduced amino acid sequence of Dr-SLC38A9. Multiple sequence alignment of SLC38A9 homologs from different species (zebrafish, humans, and mice) showed many conserved amino acid residues (Fig. 2a). Previously, broadly conserved domains among SLC38A9 homologs were characterized by structural analysis of the zebrafish Slc38a9 protein [38]. DrSLC38A9 has a sequence similar to that of the 11-amino acid transporter and transmembrane domains that are conserved among SLC38A9 homologs (Fig. 2a) [36-38]. DrSLC38A9 also has a WNTMM anchor motif, which is important for the transport of arginine, and a GTS conserved motif (Fig. 2a). Next, we constructed a phylogenetic tree by comparing the sequence of Dr-SLC38A9 with representative SLC38 family members in humans and the planarian Schmidtea mediterranea (Fig. 2b). This phylogenetic tree shows that among other human SLC38 family members, the sequence of SLC38A9 is closest to that of Dr-SLC38A9. In $S$. mediterranea, six SLC38 family member genes have been reported [28]. In comparison with the $S$. mediterranea genes, the sequence of Dr-SLC38A9 was closest to that of S. mediterranea_slc38a2 (Fig. 2b). We also confirmed that SLC38A9 is the human protein with the greatest homology to $S$ mediterranea_slc38a2 (38\% identity).

\section{Expression analyses of Dr-SLC38A9}

To examine the expression pattern of Dr-SLC38A9 in planarians, we performed whole-mount in situ hybridization (WISH) analyses on asexual and sexual worms. In asexual worms, $D r-S L C 38 A 9$ transcripts were highly expressed in the ovarian primordia on the ventral side of the worm (Fig. 3a, white arrowheads) and in the dorsal midline at the anterior and posterior regions of the pharynx (Fig. 3b, orange arrowheads), while their expression was detected weakly throughout the parenchyma (Fig. 3a, b). In sexual worms, Dr-SLC38A9 transcripts were also detected in mature ovaries at the ventral side (Fig. 3c, white arrowheads) and in the dorsal midline at the prepharyngeal region (Fig. 3d, orange arrowhead). In addition, $D r-S L C 38 A 9$ transcripts were apparent in mature testes on the dorsal side (Fig. 3d, white arrows) and yolk glands on the ventral side (Fig. 3c, magenta arrows). To confirm the histological distribution of Dr-SLC38A9 in testes and yolk glands, we carried out in situ hybridization analyses in sagittal sections of sexual worms. In the ovaries, Dr-SLC38A9 transcripts were detected in early-stage oogonia or female germline stem cells at the periphery of the main ovaries (Fig. 3f, arrowheads in circles and Fig. $3 g$ ) and satellite cells next to the main ovaries (Fig. 3f, arrowheads in dotted circles and Fig. 3g), where the germline marker Dr-nanos was strongly expressed (Fig. 3h, arrowheads and Fig. 3i) [34]. In the testes, Dr-SLC38A9 transcripts were detected in the spermatogonia at the periphery of the testes (Fig. 3j, arrows in a circle and Fig. 3k), where the germline marker Dr-nanos was also expressed (Fig. 3l, arrows in a circle and Fig. $3 \mathrm{~m})$. These results suggest that $\mathrm{Dr}$ SLC38A9 is highly expressed in early-stage germline cells during gametogenesis. In contrast, $\operatorname{Dr}-S L C 38 A 9$ was widely expressed throughout the yolk glands (Fig. 3n, arrows in circles) in sexual worms.

\section{Function of Dr-SLC38A9 in reproductive development during sexual induction}

To investigate the role of Dr-SLC38A9 in sexual induction, we performed $\operatorname{Dr}$-SLC38A9 knockdown experiments using RNA interference (RNAi) (summarized in Fig. 4a). RNAi was initiated from asexual worms. The animals were amputated once and regenerated after feeding with liver homogenate supplemented with $D r$ SLC38A9 or EGFP (control) dsRNA twice. Dr-SLC38A9 knockdown worms were able to regenerate normally. Knockdown with sexual induction was then performed using minced bodies of sexually mature $B$. brunnea supplemented with $D r-S L C 38 A 9$ or EGFP dsRNA. Expression analyses and histological analyses were carried out after 4 weeks and 6 weeks of this treatment, time points corresponding to stages 3 and 4 in terms of the development of the copulatory apparatus and genital pore, respectively. After 4 weeks of this treatment under sexual induction, we confirmed the reduced levels of $\mathrm{Dr}$ SLC38A9 mRNA by qRT-PCR (Fig. 4b, [mean (EGFP $\mathrm{KD})=1.00$, mean $(D r-S L C 38 A 9 \quad \mathrm{KD})=0.549, \mathrm{t}(5.7)=$ 3.31, $P=0.017])$. We examined the development of ovaries and the copulatory apparatus in Dr-SLC38A9-knockdown worms externally using a stereomicroscope. After 4 weeks of treatment, the percentage of Dr-SLC38A9knockdown worms that had developed ovaries and copulatory apparatuses was significantly lower than that of EGFP-knockdown (control) worms (Table 1, Fig. 4e, f). Moreover, histological examination revealed that the 
A

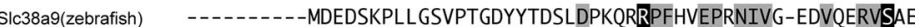
SLC38A9(human) MANMNSDSRHLGTSEVDHERDPGPMNIQFEPSDLRSKRPFCIEPTNIVNVNHVIQRVSDH SIc38a9(mouse) MASVDGDSRHL-LSEVEHEVSPGPMNIQFDSSDLRSKRPFYIEPTNIVNVNDVIQRVSDH Dr-SLC38A9(planaria) ----MSEMVSNERSALLAGTKTKNYGSDNVMIESDDIRYSSQSTRLPISFSSLDDNYSAY

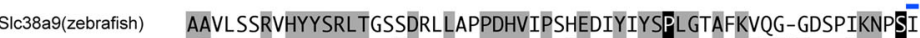
SLC38A9(human) ASAMNKRIHYYSRLTTPADKALIAPDHVVPAPEECYVYSPL GSAYKLQSYTEGYGKNTSL SIc38a9(mouse) AAAMNKRTHYYSRLTTPADKALIAPDHVVPAPEECYVYSPL GSAYKL KSYTEGYGKNTSL Dr-SLC38A9(planaria) SANPDNVSDSEISVNWSASLSRYRYYLRLGVPVIPDHVLPSRFFVLLPSOTTPPGTQSSF

Slc38a9(zebrafish) SLC38A9(human) Slc38a9(mouse)

Dr-SLC38A9(planaria)

SIc38a9(zebrafish) SLC38A9(human) Slc38a9(mouse)

Dr-SLC38A9(planaria)

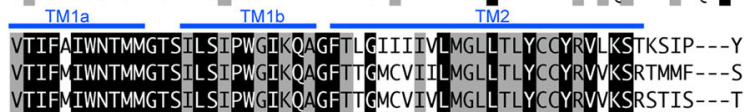
SIWNTMMGTSLLSMPWAIQDSGFALGIFLMILVAGLAFYTAYLVLKSTENLPLEPG VDTSDWEFPDV VCKYAYFGGFGKWSSLVFSLVSLIGAMVVYWVLMSNFLFNTGKFIFNYVHN LDTTSWEYPDVCRHYFGSFGOWSSLLFSLVSLIGAMIVYWVLMSNFLFNTGKFIFNFIHH SDTSTWEYPDVCKHYFGSFGOWSSLLFSLVSLIGAMIVYWVLMSNFLFNTGKFIFNFIHH

Slc38a9(zebrafish) SLC38A9(human) RTAFTSDFSDACKFYLGRPGEIVSIIFSFLALLSGLAVYYVLLCNVLYCAVNYLNGLISL

Slc38a9(mouse)

-------VNTSD-AFGTNGTE---RVICPYPDVDPHGNSS---TSLYSGS------

------INDTDTVLSTNNSN---PVICPNAGSGGRPDNS---SMIFYNN--.--

Dr-SLC38A9(planaria) NSITASLTSIIILNSNIIVSRNNNNNTFGALCPSAPLIPMKNSSLVDNLLLQDFLKSESSL

Slc38a9(zebrafish)

SLC38A9(human) $\frac{\text { TM4 }}{\text { DNSTGLEFDHWM STTNTIIPFYLILLLLPLLNFRS SASFFARFTFLGTISVIYLIFLVTYKA }}$

Slc38a9(mouse)

DT-GAQQFEKWWDKSRTVPFYLVGLLLPLLNFKS

Dr-SLC38A9(planaria)

作

Slc38a9(zebrafish)

SLC38A9(human)

Slc38a9(mouse)

Dr-SLC38A9(planaria)

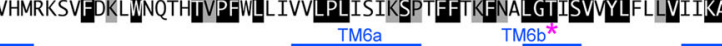

Slc38a9(zebrafish)

SLC38A9(human)

Slc38a9(mouse)

Dr-SLC38A9(planaria)
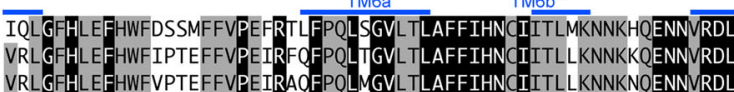

VRLGFHLEFHWFVPTEFFVPEIRAOFPOLMGVLTLAFFIHNCIITLLKNNKNQENNVRDL
VIWGIHIDFYFLT-SLSYIPNARVTIFIVLTGVGSLAFFIHNAI SSIVRSQAKPENNTRD

$\frac{\text { TM7 }}{\text { SLAYLLVGLTYLYVGVLIFAAFPSPPLSKECIEPNFLDNFPSSDILVFVARTFLLFOMTT }}$

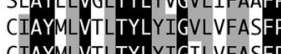

CIAYMLVTLTYLYIGILVFASFP

SIc38a9(zebrafish)

SLC38A9(human)

Slc38a9(mouse)

Dr-SLC38A9(planaria)

SIc38a9(zebrafish)

SLC38A9(human)

Slc38a9(mouse)
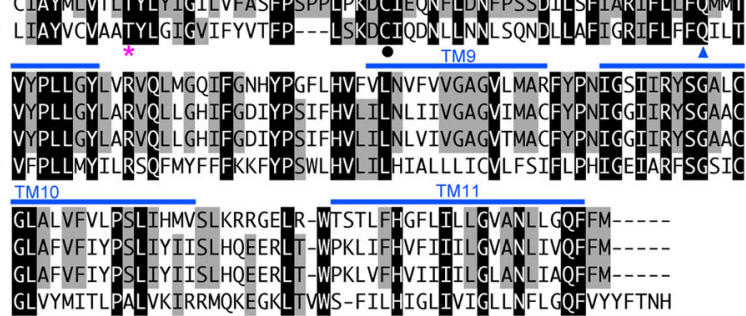

B

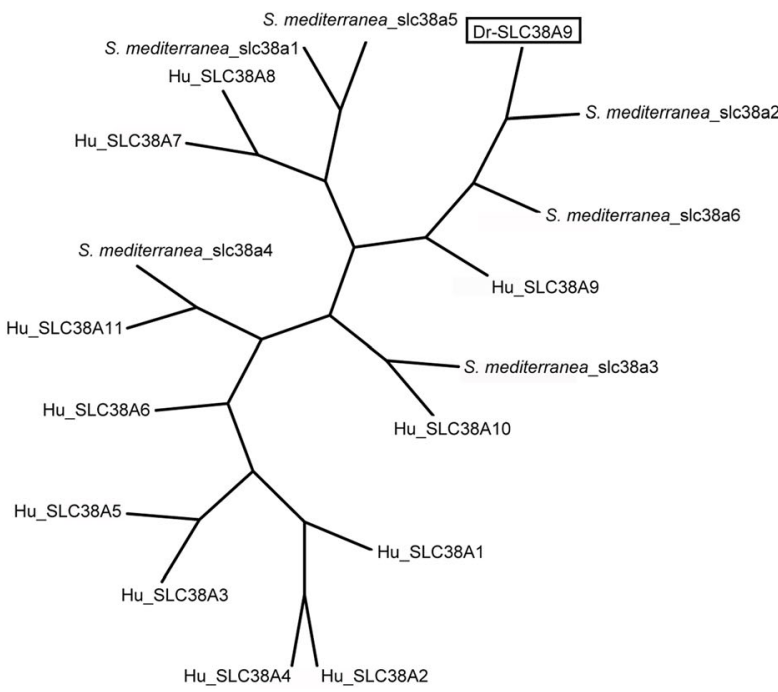

Fig. 2 (See legend on next page.) 
(See figure on previous page.)

Fig. 2 Alignment of SLC38A9 protein homologs from four animal species and phylogenetic tree of SLC38 proteins. a Multiple sequence alignment of animal SLC38A9 homologs in zebrafish (SIc38a9: NP_001073468), humans (SLC38A9: AAI01363), mice (SIc38a9: GenBank accession number NP_848861), and planarians (Dr-SLC38A9: LC225747) showed several conserved amino acid residues. Black boxes indicate residues that were identical in all aligned proteins. Gray backgrounds indicate residues that were identical in three aligned proteins. Blue lines, transmembrane regions; brown lines, loops bound to Fab; red underline, WNTMM anchor motif; orange circles, GTS conserved motif; magenta asterisks, residues bonded with TM1a; blue triangles, residues involved in Arg binding; black circles, disulfide bonds between loops 3-4 and loops 7-8. b Phylogenetic tree of human SLC38 proteins (SLC38A1: GenBank accession number NP_001070952, SLC38A2: NP_061849, SLC38A3: NP_006832, SLC38A4: NP_001137296, SLC38A5: NP_277053, SLC38A6: NP_722518, SLC38A7: NP_001356537, SLC38A8: NP_001073911, SLC38A9: NP_001336311, SLC38A10: NP_001033073, SLC38A11: NP_001186077), the planarian Schmidtea mediterranea (S. mediterranea_slc38a-1: AKN21660, S. mediterranea_slc38a-2: AKN21661, S. mediterranea_slc38a-3: AKN21662, S. mediterranea_slc38a-4: AKN21663, S. mediterranea_slc38a-5: AKN21664, S. mediterranea_slc38a-6: AKN21665) [28], and Dr-SLC38A9 of the planarian Dugesia ryukyuensis, constructed using the neighbor-joining method [29]

copulatory apparatus of Dr-SLC38A9 knockdown worms was immature (Fig. 4j) compared with that of control worms (Fig. 4i). These results suggest that Dr-SLC38A9 is involved in the development of ovaries and the copulatory apparatus during sexual induction. Next, we investigated the development of reproductive organs that could not be observed externally by qRT-PCR of $\operatorname{Dr} Y 1$, testis marker gene (previously reported as DrC_00456 [31, 34]) and Dryg, yolk gland marker gene [35], and through histological examination. Dr-SLC38A9-knockdown worms contained significantly lower levels of the testis marker $D r Y 1$ than controls (Fig. 4c, [mean (EGFP $\mathrm{KD})=1.00$, mean $(D r-S L C 38 A 9 \mathrm{KD})=0.284, \mathrm{t}(14)=4.40$, $P=0.00061])$. Moreover, histological examination revealed that the testes of Dr-SLC38A9 knockdown worms were smaller (Fig. 41) than those of control worms (Fig. $4 \mathrm{k})$. These results suggest that Dr-SLC38A9 is also involved in the development of the testes during sexual induction. After 6 weeks of treatment, the percentage of Dr-SLC38A9-knockdown worms that had developed a genital pore was significantly lower than that of controls (Table 1; Fig. 4g, h). The percentage of Dr-SLC38A9knockdown worms that had developed a copulatory apparatus at this time point was higher than that after 4 weeks of treatment (Table 1; Fig. 4e, f). These results suggest that knockdown of Dr-SLC38A9 delayed the development of the copulatory apparatus. Moreover, at the 6-week time point, Dr-SLC38A9-knockdown worms contained significantly lower levels of the yolk gland marker Dryg than controls (Fig. 4d, [mean (EGFP KD) = 1.00, mean $(D r-S L C 38 A 9 \mathrm{KD})=0.0374, \mathrm{t}(14)=3.15, P=$ $0.0071])$. In addition, histological examination revealed that $D r-S L C 38 A 9$ knockdown inhibited the development of yolk glands (Fig. 4m, n). Most importantly, these results suggest that the knockdown of Dr-SLC38A9 delayed the development of all reproductive organs during sexual induction.

\section{D-Tryptophan activates Dr-SLC38A9 expression in the reproductive organs of sexual worms}

Next, we investigated whether the expression of $\mathrm{Dr}$ SLC38A9 was related to the activity of sex-inducing substances. In this experiment, we chose sexual planarians as test worms because they contain many reproductive organs expressing Dr-SLC38A9. In the experimental sexual induction of asexual planarians, approximately 30 worms of the asexual planarians were fully sexualized by daily feeding with minced bodies of sexually mature B. brunnea worms (60 mg wet weight) for 4 weeks. We fed 15 sexual worms with approximately $120 \mathrm{mg}$ wet weight of the sexually mature B. brunnea worms or chicken liver (control) over 3 days and carried out in situ hybridization analyses using a probe for Dr-SLC38A9 RNA. Stronger DrSLC38A9 expression was detected specifically in the ovaries (Fig. 5c, d; arrowheads), testes (Fig. 5g, h; white arrows), and yolk glands (Fig. 5c, d, g, h; orange arrows) of B. brunnea-fed sexual worms than those of control worms. In particular, in the ovaries, Dr-SLC38A9 RNA was also detected in the area where supernumerary ovaries will be formed (Fig. 5c, d; magenta arrowheads) [19]. In this experiment, detection was halted according to the signal in B. brunnea-fed sexual worms, and due to the short detection time, no expression was detected in liverfed sexual worms (Fig. 5a, b, e, f). Increased Dr-SLC38A9 expression in B. brunnea was also confirmed by qRT-PCR (Fig. 5i, 2.01-fold). The question arose as to which chemical substance promoted Dr-SLC38A9 expression. Previously, we established a procedure to obtain fractions containing sex-inducing substances (namely, the $\mathrm{M0}+$ M10 fraction) from $B$. brunnea [19]. The M0 + M10 fraction derived from approximately $4 \mathrm{~g}$ wet weight of $B$. brunnea can induce full sexual induction for approximately 30 asexual planarians for a 4-week bioassay. Next, we investigated whether the expression of Dr-SLC38A9 was related to the sex-inducing substances in the $\mathrm{M} 0+$ M10 fraction using qRT-PCR analysis. Fifteen sexual worms were fed daily with a piece of food containing $\mathrm{M} 0+\mathrm{M} 10$ derived from approximately $1 \mathrm{~g}$ (wet weight) of B. brunnea, which contains a sufficient amount of sexinducing substances, over 3 days. One-way betweensubjects ANOVA was conducted to determine the effect of the sexual condition on Dr-SLC38A9 expression. There was a significant effect of sexual condition on gene expression, with $P<0.001$ for the three conditions $[\mathrm{F}(2,15)=$ 

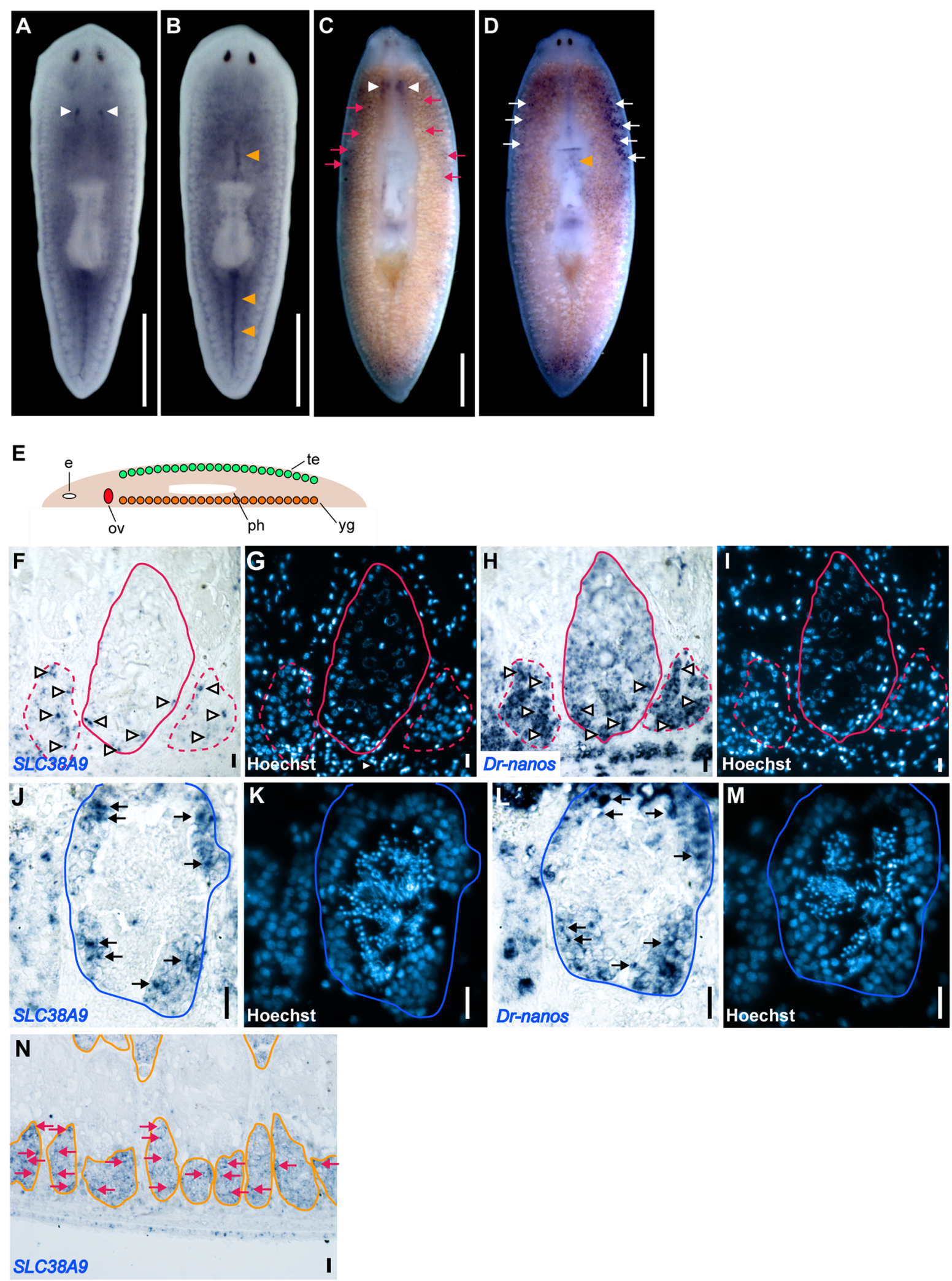

Fig. 3 (See legend on next page.) 


\section{(See figure on previous page.)}

Fig. 3 Dr-SLC38A9 mRNA expression in asexual and sexual worms. a-d Asexual (a, b) and sexual worms (c, d) were hybridized with an antisense probe to Dr-SLC38A9 mRNA. Dr-SLC38A9 transcripts are stained blue. Ventral views $(\mathbf{a}, \mathbf{c})$ and dorsal views $(\mathbf{b}$, $\mathbf{d})$ are shown with the anterior part of the worm at the top. White arrowheads indicate signals in the ovarian primordia (a) and mature ovaries (c). Orange arrowheads indicate signals in the parenchyma of the dorsal midline (b). Magenta arrows indicate signals in the yolk glands (c). White arrows indicate signals in the mature testes (d). Scale bars, a-d $1 \mathrm{~mm}$. e Schematic of a sagittal section of a sexual planarian: e, eye; ov, ovary; ph, pharynx; te, testis; yg, yolk gland. $\mathbf{f}-\mathbf{n}$ In situ hybridization of adjacent sections using an antisense probe to Dr-SLC38A9 (f, j, $\mathbf{n})$ or Dr-nanos (h, I) mRNA. g, i, $\mathbf{k}, \mathbf{m}$ Nuclei in blue. The anterior part of the worm is to the left, and the dorsal part is at the top. $\mathbf{f}$ Dr-SLC38A9 transcripts were detected at the periphery of the main ovary (magenta circle) and in satellite cells (magenta dotted circles) next to the main ovary. $\mathbf{h}$ Dr-nanos transcripts were detected at high levels in satellite cells (magenta dotted circle) next to the main ovary (magenta circle) and at low levels in the main ovary. j, I Dr-SLC38A9 and Drnanos transcripts were detected in spermatogonia at the periphery of the testes (blue circle). (N) Dr-SLC38A9 transcripts were widely detected throughout the yolk glands (orange circles). White arrowheads indicate signals of Dr-SLC38A9 (f) and Dr-nanos (h) in mature ovaries. Black arrows indicate signals of Dr-SLC38A9 (j) and Dr-nanos (I) in the mature testes. Magenta arrows indicate signals in the yolk glands (n). h, I We also detected nonspecific Dr-nanos signals in the epidermis. Scale bars, $\mathbf{f}-\mathbf{n} 20 \mu \mathrm{m}$

25.16, $P=1.61 \mathrm{e}-05]$. The resulting expression of $\mathrm{Dr}$ SLC38A9 was significantly enhanced by the M0 + M10 fraction of B. brunnea (Fig. 5i, 2.47-fold). This result suggests that the expression of $D r-S L C 38 A 9$ is related to the activity of sex-inducing substances. Next, the question arose as to which chemical substance in the M0 + M10 fraction promoted $D r-S L C 38 A 9$ expression.

Recently, we identified DL-tryptophan (Trp) as one of the sex-inducing substances contained in the M0 + M10 fraction [23]. We estimated that the M0 + M10 fraction from approximately $4 \mathrm{~g}$ (wet weight) of $B$. brunnea contains approximately $500 \mu \mathrm{g}$ of L-Trp and approximately $2.5 \mu \mathrm{g}$ of DTrp, which was able to induce a pair of immature ovaries in the asexual planarians in the 4-week feeding-assay [23]. We investigated whether the expression of Dr-SLC38A9 was related to the presence of L-Trp and D-Trp. Because the $\mathrm{M} 0+\mathrm{M} 10$ fraction derived from approximately $1 \mathrm{~g}$ (wet weight) of $B$. brunnea significantly enhanced the expression of Dr-SLC38A9 in 15 sexual worms in the 3-day bioassay (Fig. 5i), in this experiment, we set the DL-Trp content to be equal to the amount estimated to be present in the $\mathrm{M} 0+\mathrm{M} 10$ fraction derived from approximately $1 \mathrm{~g}$ (wet weight) of B. brunnea. One-way between-subjects ANOVA was conducted to compare the effects of sexual condition on $D r-S L C 38 A 9$ expression. There was a significant effect of sexual condition on gene expression, with $P<0.01$ for the three conditions $[F(3,44)=6.377, P=0.0011]$. As a result, worms fed with or without L-Trp did not show any statistically significant difference in the expression of $\mathrm{Dr}$ SLC38A9, although the mean value was higher than that of the control (Fig. 5j, 1.48-fold). In contrast, when we fed sexual worms with D-Trp, the expression of Dr-SLC38A9 was significantly higher than that in worms without D-Trp (Fig. 5j, 1.81-fold).

\section{Discussion}

\section{Dr-SLC38A9 is involved in the development of} reproductive organs during planarian sexual induction The deduced Dr-SLC38A9 protein possesses domains that are broadly conserved among SLC38A9 homologs.
In addition, phylogenetic tree analysis comparing the sequence of Dr-SLC38A9 to representative human SLC38 family members supported that Dr-SLC38A9 is more closely related to SLC38A9 than to other SLC38 family members. Therefore, we concluded that Dr-SLC38A9 is a homolog gene of human SLC38A9. We found that $D r-$ $S L C 38 A 9$ is expressed in the ovarian primordia of asexual worms. The ovarian primordia contain a small number of oogonia cells [1]. In sexual worms, Dr-SLC38A9 was expressed during the early stages of germline differentiation, specifically in oogonia and spermatogonia, where the germline marker Dr-nanos was also expressed. Thus, Dr-SLC38A9 is expressed in the early developmental stages of germline cells in both asexual and sexual worms. We demonstrated that knockdown of $\mathrm{Dr}$ SLC38A9 inhibited male and female germline development. Taken together, these data suggest that it is possible that the Dr-SLC38A9 protein activates the differentiation of oogonia and spermatogonia in gonads. We also found that Dr-SLC38A9 was widely expressed in yolk glands and demonstrated that Dr-SLC38A9 knockdown inhibited yolk gland development. This suggests that the Dr-SLC38A9 protein activates the differentiation of yolk gland cells. Most importantly, the DrSLC38A9 protein is involved in the development of both the gonads and an important somatic reproductive organ, the yolk gland. In this study, knockdown of $\mathrm{Dr}$ SLC38A9 did not completely inhibit the development of these organs. This could be because the knockdown of $D r-S L C 38 A 9$ resulted in only a $50 \%$ reduction in $D r$ SLC38A9 expression.

\section{Dr-SLC38A9 is expressed in the dorsal midline at the prepharyngeal region in asexual worms}

We found that Dr-SLC38A9 is also expressed in the dorsal midline of the prepharyngeal region of asexual and sexual worms. This region is known to express a planarian piwi homolog, Drpiwi-1, which is a marker gene of germline cells as well as pluripotent stem cells [30]. In Dugesia japonica, there is a subpopulation of pluripotent 
A
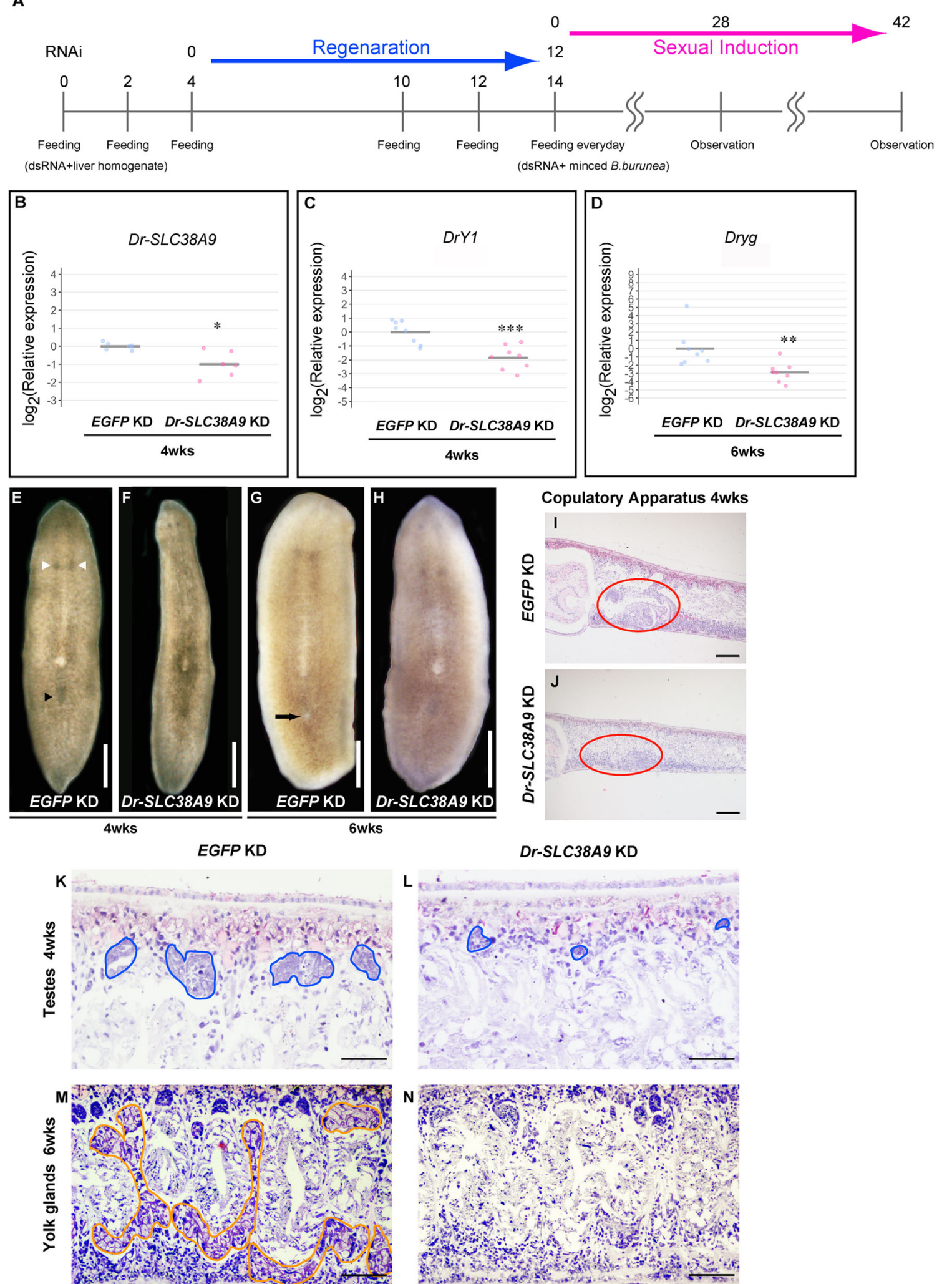

Fig. 4 (See legend on next page.) 
(See figure on previous page.)

Fig. 4 Dr-SLC38A9 knockdown phenotypes under sex-inducing conditions. a Scheme of an experimental schedule of RNA interference (RNAi) under sexual induction. b-d qRT-PCR data are shown relative to the expression level (normalized to Dr-ef1a mRNA level) in the EGFP KD worm; $\log _{2}$ (relative expression) on the vertical axis indicates $-\triangle \triangle C$ t. Each circle indicates an individual EGFP KD worm or Dr-SLC38A9 KD worm sample. The bars in the plots indicate the averages of $-\triangle \triangle \mathrm{Ct}$. $\mathbf{b}$ Dr-SLC38A9 transcript abundance after 4 weeks of treatment. Six replicates were performed. Significance was calculated using Welch's $t$-test ( $\left.{ }^{*} P<0.05\right)$. c DrY1 transcript abundance after 4 weeks of treatment. Significance was calculated using Student's $t$-test $\left({ }^{* *} P<0.001\right)$. d Dryg transcript abundance after 6 weeks of treatment. Significance was calculated using Student's t-test ( $\left.{ }^{* *} P<0.01\right)$. e, $\mathbf{f}$ Development of ovaries (white arrowheads) and copulatory apparatus (black arrowhead). A ventral view is shown, with the anterior of the worm at the top. $\mathbf{g}$, $\mathbf{h}$ Development of the genital pore (black arrow). A ventral view is shown, with the anterior of the worm at the top. Scale bar, e-h $1 \mathrm{~mm}$. i-I Transverse sections from asexual worms fed daily with minced $B$. brunnea worms supplemented with EGFP (control; i, $\mathbf{k}, \mathbf{m}$ ) or Dr-SLC38A9 $\mathbf{j}, \mathbf{I}, \mathbf{n}$ ) dsRNA for 6 weeks. The anterior part of the worm is to the left, and the dorsal part is at the top. $\mathbf{i}, \mathbf{j}$ HE staining of the copulatory apparatus (red circles) after 4 weeks of treatment. $\mathbf{k}$, I HE staining of the testes (blue circles) after 4 weeks of treatment. $\mathbf{m}, \mathbf{n}$ HE staining of the yolk glands (orange circles) after 6 weeks of treatment. Yolk glands did not develop in the Dr-SLC38A9knockdown worms. Scale bars, i, j $200 \mu \mathrm{m}, \mathbf{k}$, I $50 \mu \mathrm{m}, \mathbf{m}, \mathbf{n} 100 \mu \mathrm{m}$

stem cells in the same region defined by DjPiwi-1, another piwi family member that is not homologous to Drpiwi-1 [39]. Therefore, we speculate that Dr-SLC38A9-expressing cells in the dorsal midline at the prepharyngeal region might be a subpopulation of pluripotent stem cells that have the potential to differentiate into germline cells. This speculation is supported by two pieces of evidence. First, when we fed asexual worms food supplemented with DTrp for 7 weeks, a Dr-nanos-positive cell mass was induced at the dorsal midline (Fig. S3A, B, D), although during normal sexual induction, the expression of Dr-nanos was not found in the dorsal midline (Fig. S3E). Second, an ectopic Dr-nanos signal was detected in the same region of starved sexual worms, although this signal was not detected in normal sexual worms [40]. Starved sexual worms have no externally recognizable ovaries or copulatory apparatus, but they become fully sexual after being fed chicken liver once a week [40]. Thus, it is possible that Dr-nanos-positive cells in the dorsal midline at the prepharyngeal region contribute to sexual development. In future research, we will investigate whether Dr-SLC38A9 is expressed in the dorsal midline at the prepharyngeal region of starved sexual worms.

\section{Dr-SLC38A9 expression is enhanced by D-Trp}

In the present study, we also demonstrated that $D r-$ SLC38A9 expression is related to the activity of D-Trp.
Interestingly, $\mathrm{D}-\mathrm{Trp}$ was able to enhance the expression of $D r-S L C 38 A 9$ as well as the M0 + M10 fraction. Therefore, the $D r-S L C 38 A 9$ expression-inducing substance in the $\mathrm{M} 0+\mathrm{M} 10$ fraction is considered to be D-Trp, although it is possible that other Dr-SLC38A9 expressioninducing substances are also included. Thus, we propose that D-Trp activates $D r-S L C 38 A 9$ function in reproductive organs. Moreover, we demonstrated that L-Trp did not promote SLC38A9 expression, because although the average expression in L-Trp-fed worms was higher than that of controls, the difference was not statistically significant. Both L-Trp and D-Trp have ovarian-inducing activity [23], although their effective pathways could be different. In fact, it has been suggested that L-Trp is metabolized to serotonin and functions in ovarian induction [27]. L-Trp can be converted to D-Trp by racemase activity; however, tryptophan racemase has not been isolated from animals. Considering the differences in the activity of L-Trp and D-Trp, if such a racemase even exists, its function is presumed to be weak.

\section{Molecular function of SLC38A9}

Transporters play key roles in many biological processes that are regulated by amino acids [41]. The solute carrier (SLC) superfamily is the largest group of membrane transport proteins and comprises 55 gene families, having at least 362 putatively functional protein-coding

Table 1 Dr-SLC38A9 RNAi knockdown during sexual induction

\begin{tabular}{|c|c|c|c|c|}
\hline Treatment period & Test food $^{a}$ & $\begin{array}{l}\text { Number of worms developing } \\
\text { a pair of ovaries }(\%)^{\mathbf{b}}\end{array}$ & $\begin{array}{l}\text { Number of worms developing } \\
\text { copulatory apparatus }(\%)^{b}\end{array}$ & $\begin{array}{l}\text { Number of worms developing } \\
\text { a genital pore }(\%)^{\mathbf{b}}\end{array}$ \\
\hline \multirow[t]{2}{*}{ Week 4} & EGFP dsRNA & $29 / 29(100)$ & $21 / 29(72.4)$ & $0 / 29(0)$ \\
\hline & Dr-SLC38A9 dsRNA & $22 / 29(75.9)^{* c}$ & $5 / 29(17.2)^{* * d}$ & $0 / 29(0)$ \\
\hline \multirow[t]{2}{*}{ Week 6} & EGFP dsRNA & 18/18 (100) & 18/18 (100) & 14/18 (77.8) \\
\hline & Dr-SLC38A9 dsRNA & 19/19 (100) & 15/19 (78.9) n.s. & $4 / 19(21.1)^{* * *^{f}}$ \\
\hline
\end{tabular}

${ }^{a}$ Asexual worms were fed minced B. brunnea worms supplemented with EGFP (control), daily or Dr-SLC38A9 dsRNA for up to 6 weeks (summarized in Fig. 4)

${ }^{b}$ Development of ovaries, copulatory apparatus, and a genital pore were observed externally using a stereoscopic microscope

'Statistical significance was calculated using one-sided Fisher's exact test $\left({ }^{*} P=0.0052\right)$

${ }^{d}$ Statistical significance was calculated using the Chi-squared test $\left(* * x^{2}(1, N=58)=17.8, P<0.001\right)$

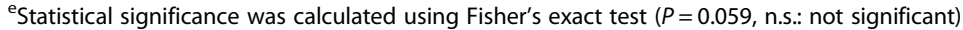

${ }^{f}$ Statistical significance was calculated using the Chi-squared test with Yates' continuity correction $\left({ }^{* * *} \mathrm{x}^{2}(1, N=37)=9.7, P=0.0018\right)$ 

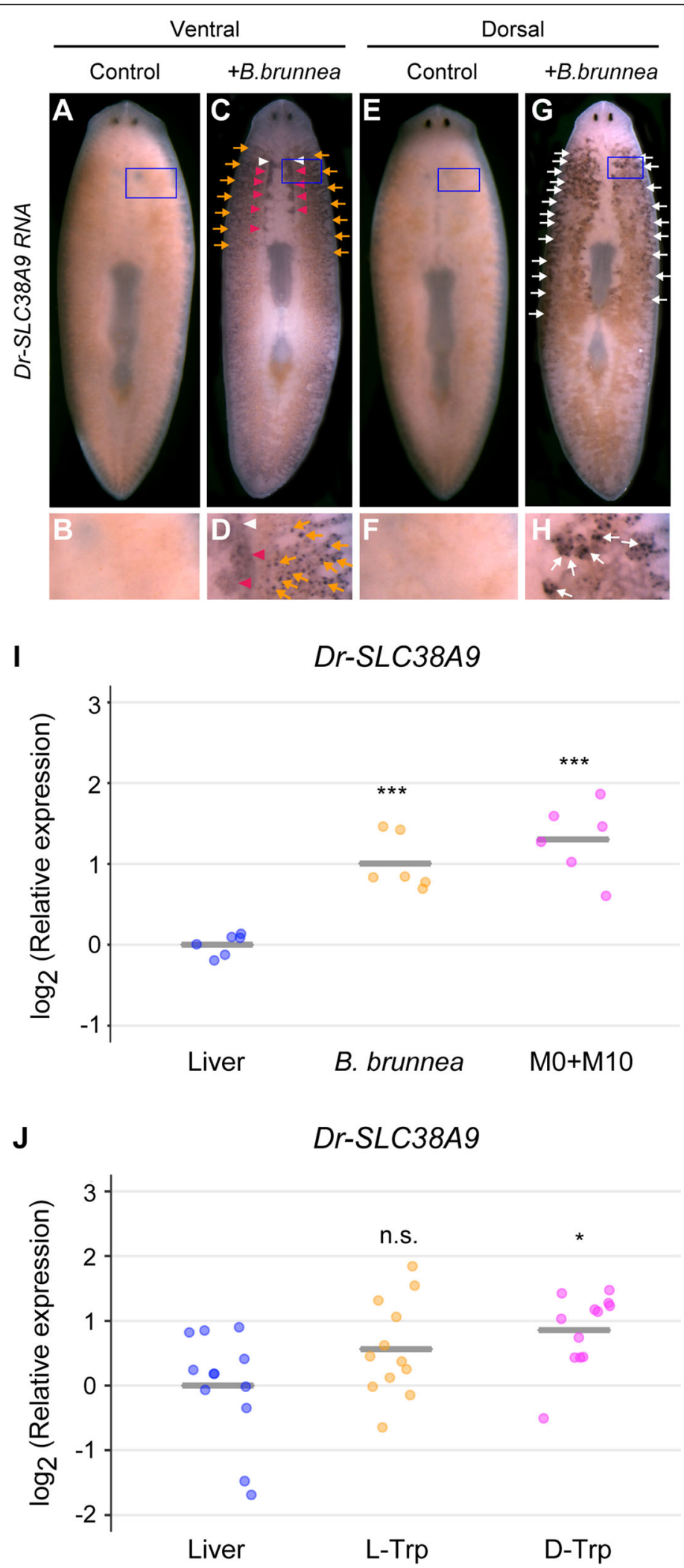

Fig. 5 (See legend on next page.) 
(See figure on previous page.)

Fig. 5 Induction of the expression of Dr-SLC38A9 upon treatment with sex-inducing substances. a-h Whole-mount in situ hybridization of DrSLC38A9 mRNA in sexual worms fed chicken liver (Control; $\mathbf{a}, \mathbf{b}, \mathbf{e}, \mathbf{f}$ ) or minced B. brunnea worms $(\mathbf{c}, \mathbf{d}, \mathbf{g}, \mathbf{h})$ daily for 3 days. Dr-SLC38A9 transcripts are stained blue. Ventral views (a-d) and dorsal views (e-h) are shown, with the anterior part of the worm at the top. $\mathbf{b}, \mathbf{d}, \mathbf{f}, \mathbf{h} H i g h e r$ magnification views of areas inside blue squares in panels $(\mathbf{a}, \mathbf{c}, \mathbf{e}$, and $\mathbf{g})$. White arrowheads indicate signals in the ovaries (c, $\mathbf{d})$. Magenta arrowheads indicate signals in the area where supernumerary ovaries will be formed $(\mathbf{c}, \mathbf{d})$. Orange arrows indicate signals in the yolk glands (c, d). Black arrows indicate signals in the testes $(\mathbf{g}, \mathbf{h}) . \mathbf{i}, \mathbf{j}$ qRT-PCR data are shown relative to the expression level (normalized to Dr-ef1 a mRNA level) in the liver-fed worm, and $\log _{2}$ (relative expression) on the vertical axis indicates $-\Delta \Delta C \mathrm{C}$. The bars in the plots indicate the averages of $-\triangle \Delta C$ t. Asterisks indicate significant differences compared with liver-fed worms (Tukey's HSD test: ${ }^{*} P<0.05$; ${ }^{* * *} P<0.001$; n.S., not significant). i Six circles indicate individual samples of liver-fed worms, worms fed B. brunnea, and worms fed liver supplemented with the M0 $+\mathrm{M} 10$ fraction. $\mathbf{j}$ Twelve circles indicate individual samples of liver-fed worms and worms fed liver supplemented with L-Trp or D-Trp

genes in the human genome [42]. In humans, the SLC38 family consists of 11 members and encodes amino acid transporters known as sodium-coupled amino acid transporters (SNATs) [43]. Members of the SLC38 family are functionally classified as neutral amino acid transporters [43]. One of the genes in this family is involved in reproduction and embryogenesis, and mouse Slc38a4 is important for maternal placentation [44]. As mentioned above, D-Trp can activate Dr-SLC38A9 expression. In Arabidopsis, expression of the ATP-binding cassette transporter gene AtABCG40 is enhanced by its substrate, abscisic acid [45]. This suggests the possibility that the substrate activates its transporter. Therefore, we speculate that D-Trp might be a substrate of DrSLC38A9. This speculation is supported by the fact that Dr-SLC38A9 is expressed throughout yolk glands, which contain a large amount of Trp [23]. Recently, it was reported that human SLC38A9 transports L-arginine (LArg) and acts as an Arg sensor [36, 37]. SLC38A9 function is essential for the activation of mammalian target of rapamycin complex 1 (mTORC1) [36, 37], which controls cell growth and proliferation [46]. Therefore, we also speculate that Dr-SLC38A9 may act as a D-Trp sensor to control cell growth and proliferation during sexual induction. The current study suggests that D-Trp is taken directly into the ovaries and testis via the DrSLC38A9 transporter. Nevertheless, the biological function of D-Trp in the ovaries and testes remains unknown. A possibility is that it might act as a ligand for nuclear receptors. Additionally, qPCR analysis implied that TR33723 | c0_g1_i1 is also highly expressed in the yolk glands, and TR37685|c0_g2_i3 is expressed in the ovaries. We consider that in future works, it will be important to study whether TR33723|c0_g1_i1, TR37685|c0_g2_i3, and Dr-SLC38A9 proteins are capable of transporting D-Trp.

\section{Conclusions}

D-Trp was the first substance to be identified as sexinducing in the sexual induction of planarian D. ryukyuensis. In the present study, to investigate the mechanism of sexual induction of planaria by D-Trp, we isolated a putative amino transporter gene, Dr-SLC38A9, activated by D-Trp. Considering its expression and function, $D r-S L C 38 A 9$ could play a role in the early developmental stages of germline cells and yolk glands. Its function in yolk glands could be related to the enrichment of Trp therein. Thus, the functional analysis of $D r$ SLC38A9 in this study is an important first step in clarifying the mechanism of planarian sexual induction by DTrp.

\section{Supplementary Information}

The online version contains supplementary material available at https://doi. org/10.1186/s40851-021-00173-z.

\begin{abstract}
Additional file 1: Figure S1. Five stages of sexualization in the planarian D. ryukyuensis. The $\mathrm{OH}$ strain of the planarian D. ryukyuensis begins to develop reproductive organs upon switching from the asexual to the sexual state. The process can be roughly divided into five stages based on the development of reproductive organs [18]. Briefly, the asexual worm has ovarian primordia (op) at the ventral side. In stage 1, the ovary (ov), with an increasing number of oogonia, starts to form and becomes externally apparent. In stage 2, maturing ovaries with developing oocytes form. In stage 3 , the primordial testis (te) at the dorsal side and primordial yolk glands (yg) at the ventral sides [35] form, and the copulatory apparatus (ca) becomes externally apparent at the ventral side. In stage 4, the genital pore (gp) becomes externally apparent at the ventral side. In stage 5, the testis (te) on the dorsal side and the yolk glands (yg) on both the ventral and dorsal sides mature. The worm is then ready for mating and egg laying. Note that the planarian body size changes because of the feeding procedure used for sexual induction [1]. If the food does not contain sex-inducing substances, asexual worms become larger without undergoing reproductive development.
\end{abstract}

Additional file 2: Figure S2. Nucleotide sequence of the Dr-SLC38A9 gene and its predicted amino acid sequence. The isolated cDNA has a 78-bp 5' untranslated region and an 84-bp 3' untranslated region. A polyadenylation signal (AATAAA) is located $13 \mathrm{bp}$ upstream of the beginning of the poly(A) tail. Dr-SLC38A9 contains an open reading frame encoding a 585-amino acid polypeptide.

Additional file 3: Figure S3. Ectopic germline induction by D-Trp administration in the dorsal midline. (A, B) After we fed asexual worms food supplemented with D-Trp for 7 weeks, a serial sagittal section of a DTrp-fed worm was prepared. (A) A section stained with hematoxylin and eosin. (B) In situ hybridization of Dr-nanos using an adjacent section. Red arrowheads represent a germ-like cell mass with a positive Dr-nanos signal. The dorsal side is at the top. In, intestine. Scale bar, $100 \mu \mathrm{m}$. (C-E) Whole-mount in situ hybridization of Dr-nanos. The test worms were fed (C) chicken liver homogenate (control) and (D) Trp for 7 weeks. (E) Stage 3 worms. Red arrowheads represent Dr-nanos expression in the dorsal midline at the prepharyngeal region, whereas blue arrowheads represent Dr-nanos expression in the presumptive region of the testes. Scale bars, $2 \mathrm{~mm}$. Red and blue arrowheads represent Dr-nanos expression in the dorsal midline at the prepharyngeal region and presumptive region of 
the testes. These ectopic germlines were induced by administration of LTrp, as well as D-Trp.

Additional file 4: Supplementary Table S1. Primer sets used for qRTPCR

Additional file 5: Supplementary Data Sheet S1. The raw data of qRT-PCR analyses for Fig. 1, 4 and 5.

\section{Acknowledgments}

We thank the members of our laboratory for their valuable comments. We would like to thank Editage (www.editage.jp) for English language editing.

\section{Authors' contributions}

$\mathrm{TM}$ and $\mathrm{KK}$ supervised the project and discussed the results. TM, MI, and KK conducted and designed the experiments. KS, GN, and RF supported qPCR analysis. TM wrote the manuscript. All authors read and approved the final manuscript.

\section{Funding}

This work was supported by two Grants-in-Aid for Scientific Research on Innovative Areas (grant numbers $16 \mathrm{H} 01249$ and $19 \mathrm{H} 05236$ to K.K.); a Grantin-Aid for Scientific Research (B) (grant number 19H03256, to K.K.); two Grants-in-Aid for Scientific Research (C) (grant numbers 22603010 and 18 K06323 to T.M.); a Grant-in-Aid for Challenging Exploratory Research (grant number 25650103, to T.M. and 18 K19318, to K.K.); and a Grant-in-Aid for Young Scientists (19 K16175, to K.S.) from the Ministry of Education, Culture, Sports, Science and Technology, Japan. This work was also supported by a grant for Basic Science Research Projects from The Sumitomo Foundation to T.M. and a grant from The Ryobi Teien Memorial Foundation to T.M.

\section{Availability of data and materials}

Data sharing is not applicable to this article, as no datasets were generated during the current study.

\section{Declarations}

Ethics approval and consent to participate

Not applicable.

\section{Consent for publication}

Not applicable.

\section{Competing interests}

The authors declare that they have no competing interests.

\section{Author details}

${ }^{1}$ Advanced Science Course, Department of Integrated Science and Technology, National Institute of Technology, Tsuyama College, 624-1 Numa, Tsuyama, Okayama 708-8509, Japan. '2Faculty of Agriculture and Life Science, Hirosaki University, 3 Bunkyo-cho, Hirosaki, Aomori 036-8561, Japan. ${ }^{3}$ Department of Stem Cell Biology and Medicine, Graduate School of Medical Science, Kyushu University, 3-1-1 Maidashi, Higashi-ku, Fukuoka 812-8582, Japan. ${ }^{4}$ Department of Biology, Research and Education Center for Natural Sciences, Keio University, 4-1-1 Hiyoshi, Kohoku-ku, Yokohama, Kanagawa 223-8521, Japan

Received: 9 August 2020 Accepted: 10 March 2021

Published online: 20 March 2021

\section{References}

1. Kobayashi K, Koyanagi R, Matsumoto M, Cebrera PJ, Hoshi M. Switching from asexual to sexual reproduction in the planarian Dugesia ryukyuensis: bioassay system and basic description of sexualizing process (reproductive biology). Zool Sci. 1999;16(2):291-8. https://doi.org/10.2108/zsj.16.291.

2. Sunanaga $\mathrm{T}$, Inubushi $\mathrm{H}$, Kawamura K. Piwi-expressing hemoblasts serve as germline stem cells during postembryonic germ cell specification in colonial ascidian, Botryllus primigenus. Dev Growth Differ. 2010;52(7):603-14. https://doi.org/10.1111/j.1440-169X.2010.01196.x PubMed PMID: 20887561.

3. Myohara M, Yoshida-Noro C, Kobari F, Tochinai S. Fragmenting oligochaete Enchytraeus japonensis: a new material for regeneration study. Develop
Growth Differ. 1999;41(5):549-55. https://doi.org/10.1046/j.1440-169x.1999. 00455.x Epub 1999/11/02. PubMed PMID: 10545027.

4. Kato $Y$, Kobayashi $K$, Watanabe $H$, Iguchi T. Environmental sex determination in the branchiopod crustacean Daphnia magna: deep conservation of a Doublesex gene in the sex-determining pathway. PLoS Genet. 2011;7(3): e1001345. https://doi.org/10.1371/journal.pgen.1001345 Epub 2011/04/02 PubMed PMID: 21455482; PubMed Central PMCID: PMC3063754.

5. Aboobaker AA. Planarian stem cells: a simple paradigm for regeneration. Trends Cell Biol. 2011;21(5):304-11. https://doi.org/10.1016/j.tcb.2011.01.005 Epub 2011/03/01. PubMed PMID: 21353778.

6. Baguna J. The planarian neoblast: the rambling history of its origin and some current black boxes. Int J Dev Biol. 2012;56(1-3):19-37. https://doi. org/10.1387/ijdb.113463jb Epub 2012/01/19. PubMed PMID: 22252540.

7. Issigonis M, Newmark PA. From worm to germ: germ cell development and regeneration in planarians. Curr Top Dev Biol. 2019;135:127-53. Epub 2019/ 06/04. PubMed PMID: 31155357. https://doi.org/10.1016/bs.ctdb.2019.04.001.

8. Curtis $W$. The life histry, the normal fission and the reproductive organs of planaria maculata. Proc Boston Soc Nat Hist. 1902;30:515-59.

9. Kenk R. Sexual and asexual reproduction in Euplanaria tigrina (Girard). Biol Bull. 1937;73(2):280-94. https://doi.org/10.2307/1537589.

10. Hyman L. North American triclad Turbellaria. IX. The priority of Dugesia Girard 1850 over Euplanaria Hesse 1897 with notes on American species of Dugesia. Trans Am Micros Soc. 1939;58:265-75.

11. Vowinckel $C$. The role of illumination and temparature in the control of sexual reproduction in the planarian Dugesia tigrina (Girard). Biol Bull. 1970; 138(1):77-87. https://doi.org/10.2307/1540293.

12. Vowinckel C, Marsden JR. Reproduction of Dugesia tigrina under short-day and long-day conditions at different temparatures. I. Sexually derived individuals. J Embryol Exp Morphol. 1971;26(3):587-98.

13. Sato K, Shibata N, Orii H, Amikura R, Sakurai T, Agata K, Kobayashi S, Watanabe K. Identification and origin of the germline stem cells as revealed by the expression of nanos-related gene in planarians. Develop Growth Differ. 2006;48(9):615-28. Epub 2006/11/23. PubMed PMID: 17118016. https://doi.org/10.1111/j.1440-169X.2006.00897.x.

14. Kenk R. Induction of sexuality in the asexual from of Dugesia tigrina. J Exp Zool. 1941:87(1):55-69. https://doi.org/10.1002/jez.1400870105.

15. Okugawa Kl. An experimental study of sexual induction in the asexual form of Japanese fresh-water planarian, Dugesia gonocephala (Dugès). Bull Kyoto Gakugei Univ. 1957;11:8-26.

16. Grasso M, Benazzi M. Genetic and physiologic control of fissioning and sexuality in planarians. J Embryol Exp Morphol. 1973;30(2):317-28.

17. Sakurai T. Sexual induction by feeding in an asexual strain of the fresh-water planarian, Dugesia-Japonica-Japonica. Annot Zool Jpn. 1981;54(2):103-12 PubMed PMID: WOS:A1981LW57500004

18. Kobayashi K, Hoshi M. Switching from asexual to sexual reproduction in the planarian Dugesia ryukyuensis: change of the fissiparous capacity along with the sexualizing process. Zool Sci. 2002;19(6):661-6. Epub 2002/07/20. PubMed PMID: 12130793-6. https://doi.org/10.2108/zsj.19.661.

19. Kobayashi K, Hoshi M. Sex-inducing effect of a hydrophilic fraction on reproductive switching in the planarian Dugesia ryukyuensis (Seriata, Tricladida). Front Zool. 2011;8(1):23. Epub 2011/10/19. PubMed PMID: 22005169; PubMed Central PMCID: PMC3215924. https://doi.org/10.1186/1 742-9994-8-23.

20. Martin-Duran JM, Monjo F, Romero R. Planarian embryology in the era of comparative developmental biology. Int J Dev Biol. 2012;56(1-3):39-48. Epub 2012/03/28. PubMed PMID: 22450993. https://doi.org/10.1387/ ijdb.113442jm.

21. Sluys R. A monograph of the marine triclads. Routledge \& CRC Press; 2017.

22. Nakagawa H, Sekii K, Maezawa T, Kitamura M, Miyashita S, Abukawa M, et al. A comprehensive comparison of sex-inducing activity in asexual worms of the planarian Dugesia ryukyuensis: the crucial sex-inducing substance appears to be present in yolk glands in Tricladida. Zoological Lett. 2018;4:14 Epub 2018/06/27. PubMed PMID: 29942643; PubMed Central PMCID: PMCP MC5996458. https://doi.org/10.1186/s40851-018-0096-9.

23. Kobayashi K, Maezawa T, Tanaka H, Onuki H, Horiguchi Y, Hirota H, Ishida T, Horiike K, Agata Y, Aoki M, Hoshi M, Matsumoto M. The identification of -tryptophan as a bioactive substance for postembryonic ovarian development in the planarian Dugesia ryukyuensis. Sci Rep. 2017:7(1):45175. https://doi.org/10.1038/srep45175. PubMed PMID: 28338057.

24. Kawakatsu MOI, Tamura S, Sugino H. Studies on the morphology, karyology and taxonomy of the Japanese freshwater planarian Dugesia japonica 
Ichikawa et Kawakastu, with a description of a new subspecies, Dugesia japonica ryukyuensis subspec. Bull Fuji Womens Coll. 1976;23:127-32.

25. Kawakatsu MOI, Tamura S. Taxonomy and geographical distribution of Dugesia 465 japonica and D. ryukyuensis in the Far East. Hydrobiologia. 1995;305(1-3):55-61. https://doi.org/10.1007/BF00036363.

26. Ijima IKT. Preliminary descriptions of Japanese Triclads. Annot Zool Jpn. 1916;9:153-71

27. Sekii K, Yorimoto S, Okamoto H, Nagao N, Maezawa T, Matsui Y, et al. Transcriptomic analysis reveals differences in the regulation of amino acid metabolism in asexual and sexual planarians. Sci Rep. 2019;9(1):6132. https:// doi.org/10.1038/s41598-019-42025-z PubMed PMID: 30992461; PubMed Central PMCID: PMCPMC6467871

28. Thi-Kim Vu H, Rink JC, McKinney SA, McClain M, Lakshmanaperumal N, Alexander $R$, et al. Stem cells and fluid flow drive cyst formation in an invertebrate excretory organ. Elife. 2015;4. https://doi.org/10.7554/eLife.074 05 PubMed PMID: 26057828; PubMed Central PMCID: PMCPMC4500094.

29. Saitou N, Nei M. The neighbor-joining method: a new method for reconstructing phylogenetic trees. Mol Biol Evol. 1987;4(4):406-25. PubMed PMID: 3447015. https://doi.org/10.1093/oxfordjournals.molbev.a040454.

30. Nakagawa H, Ishizu H, Hasegawa R, Kobayashi K, Matsumoto M. Drpiwi-1 is essential for germline cell formation during sexualization of the planarian Dugesia ryukyuensis. Dev Biol. 2012;361(1):167-76. Epub 2011/10/26. PubMed PMID: 22024321. https://doi.org/10.1016/j.ydbio.2011.10.014.

31. Ishizuka H, Maezawa T, Kawauchi J, Nodono H, Hirao Y, Nishimura O, Nakagawa H, Sekii K, Tasaka K, Tarui H, Agata K, Hoshi M, Kobayashi K, Sakakibara Y, Matsumoto M. The Dugesia ryukyuensis database as a molecular resource for studying switching of the reproductive system. Zool Sci. 2007;24(1):31-7. Epub 2007/04/06. PubMed PMID: 17409714. https://doi. org/10.2108/zsj.24.31.

32. R Development Core Team RFfSC, Vienna, Austria. R: a language and environment for statistical computing. 2004.

33. Kobayashi K, Maezawa T, Nakagawa H, Hoshi M. Existence of two sexual races in the planarian species switching between asexual and sexual reproduction. Zool Sci. 2012;29(4):265-72. Epub 2012/04/04. PubMed PMID: 22468837. https://doi.org/10.2108/zsj.29.265.

34. Nakagawa H, Ishizu H, Chinone A, Kobayashi A, Matsumoto M. The Dr-nanos gene is essential for germ cell specification in the planarian Dugesia ryukyuensis. Int J Dev Biol. 2012;56(1-2-3):165-71. Epub 2012/03/28. PubMed PMID: 22451004. https://doi.org/10.1387/ijdb.113433hn.

35. Hase S, Kobayashi K, Koyanagi R, Hoshi M, Matsumoto M. Transcriptional pattern of a novel gene, expressed specifically after the point-of-no-return during sexualization, in planaria. Dev Genes Evol. 2003;212(12):585-92. Epub 2003/01/22. PubMed PMID: 12536322. https://doi.org/10.1007/s00427-002-02 88-2.

36. Wang S, Tsun ZY, Wolfson RL, Shen K, Wyant GA, Plovanich ME, et al. Metabolism. Lysosomal amino acid transporter SLC38A9 signals arginine sufficiency to mTORC1. Science. 2015;347(6218):188-94. https://doi.org/1 0.1126/science.1257132 PubMed PMID: 25567906; PubMed Central PMCID: PMCPMC4295826

37. Rebsamen M, Pochini L, Stasyk T, de Araujo ME, Galluccio M, Kandasamy RK, et al. SLC38A9 is a component of the lysosomal amino acid sensing machinery that controls mTORC1. Nature. 2015;519(7544):477-81. https:// doi.org/10.1038/nature14107 PubMed PMID: 25561175; PubMed Central PMCID: PMCPMC4376665.

38. Lei HT, Ma J, Sanchez Martinez S, Gonen T. Crystal structure of argininebound lysosomal transporter SLC38A9 in the cytosol-open state. Nat Struct Mol Biol. 2018;25(6):522-7. Epub 2018/06/07. PubMed PMID: 29872228. https://doi.org/10.1038/s41594-018-0072-2.

39. Rossi L, Salvetti A, Lena A, Batistoni R, Deri P, Pugliesi C, Loreti E, Gremigni V. Djpiwi-1, a member of the PAZ-Piwi gene family, defines a subpopulation of planarian stem cells. Dev Genes Evol. 2006;216(6):335-46. Epub 2006/03/15. PubMed PMID: 16532341. https://doi.org/10.1007/s00427-006-0060-0.

40. Sekii K, Kobayashi K. Sex-inducing substances breakdown dormancy in planarian postembryonic reproductive development. In: Advances in invertebrate (neuro) endocrinology: a collection of reviews in the postgenomic era volume 1: phyla other than Anthropoda, vol. 1; 2020. p. 25-62.

41. Palacin M, Estevez R, Bertran J, Zorzano A. Molecular biology of mammalian plasma membrane amino acid transporters. Physiol Rev. 1998;78(4):9691054. PubMed PMID: 9790568. https://doi.org/10.1152/physrev.1998.78.4.969.

42. He L, Vasiliou K, Nebert DW. Analysis and update of the human solute carrier (SLC) gene superfamily. Hum Genomics. 2009;3(2):195-206. PubMed
PMID: 19164095; PubMed Central PMCID: PMC2752037. https://doi.org/10.11 86/1479-7364-3-2-195.

43. Hagglund MG, Sreedharan S, Nilsson VC, Shaik JH, Almkvist IM, Backlin S, et al. Identification of SLC38A7 (SNAT7) protein as a glutamine transporter expressed in neurons. J Biol Chem. 2011;286(23):20500-11. https://doi.org/1 0.1074/jbc.M110.162404 PubMed PMID: 21511949; PubMed Central PMCID: PMC3121473.

44. Matoba S, Nakamuta S, Miura K, Hirose M, Shiura H, Kohda T, et al. Paternal knockout of SIc38a4/SNAT4 causes placental hypoplasia associated with intrauterine growth restriction in mice. Proc Natl Acad Sci U S A. 2019; 116(42):21047-53. https://doi.org/10.1073/pnas.1907884116 Epub 2019/10/ 02. PubMed PMID: 31570606; PubMed Central PMCID: PMCPMC6800347.

45. Kang J, Hwang JU, Lee M, Kim YY, Assmann SM, Martinoia E, Lee Y. PDRtype $A B C$ transporter mediates cellular uptake of the phytohormone abscisic acid. Proc Natl Acad Sci U S A. 2010;107(5):2355-60. https://doi. org/10.1073/pnas.0909222107 PubMed PMID: 20133880; PubMed Central PMCID: PMC2836657.

46. Zheng L, Zhang W, Zhou Y, Li F, Wei H, Peng J. Recent advances in understanding amino acid sensing mechanisms that regulate mTORC1. Int J Mol Sci. 2016;17(10). https://doi.org/10.3390/ijms17101636 PubMed PMID: 27690010; PubMed Central PMCID: PMCPMC5085669.

\section{Publisher's Note}

Springer Nature remains neutral with regard to jurisdictional claims in published maps and institutional affiliations.

\section{Ready to submit your research? Choose BMC and benefit from:}

- fast, convenient online submission

- thorough peer review by experienced researchers in your field

- rapid publication on acceptance

- support for research data, including large and complex data types

- gold Open Access which fosters wider collaboration and increased citations

- maximum visibility for your research: over $100 \mathrm{M}$ website views per year

At $\mathrm{BMC}$, research is always in progress.

Learn more biomedcentral.com/submissions 